\title{
Gastrin-induced apoptosis contributes to carcinogenesis in the stomach
}

\author{
Guanglin Cui ${ }^{1,3}$, Shigeo Takaishi ${ }^{2}$, Wandong Ai $^{2}$, Kelly S Betz ${ }^{2}$, Jon Florholmen ${ }^{3}$, \\ Theodore J Koh ${ }^{1}$, JeanMarie Houghton ${ }^{1}$, D Mark Pritchard ${ }^{4}$ and Timothy C Wang ${ }^{2}$ \\ ${ }^{1}$ Division of Gastroenterology, Department of Medicine, University of Massachusetts Medical School, \\ Worcester, MA, USA; ${ }^{2}$ Division of Digestive and Liver Disease, Department of Medicine, Columbia University, \\ College of Physicians and Surgeons, New York, NY, USA; ${ }^{3}$ Laboratory of Gastroenterology, Institute of Clinical \\ Medicine, University of Tromso, Tromso, Norway and ${ }^{4}$ Division of Gastroenterology, University of Liverpool, \\ Liverpool, UK
}

\begin{abstract}
Hypergastrinemia in INS-GAS mice leads to accelerated carcinogenesis of the stomach, but the mechanisms have not been well defined. We investigated the possible role of gastrin-induced gastric cell apoptosis in the development of gastric cancer. We examined apoptosis and the expression of $\mathrm{Bcl}-2$ family proteins in INS-GAS mice of different ages, as well as in gastrin-deficient (GAS-KO) mice after gastrin-17 (G-17) infusion. In addition, we studied the effects of the gastrin/cholecystokinin-2 (CCK-2) receptor antagonist YF476 and/or histamine H2 (H-2) receptor antagonist loxtidine on apoptosis and atrophy in INS-GAS mice with or without Helicobacter felis $(H$. felis) infection. INS-GAS mice had age-associated increases in Bax protein expression and decreases in Bcl2 protein expression, along with increased glandular and epithelial cell apoptosis. At 8-week gastrin infusions in GAS-KO mice resulted in a similar pattern of altered Bax and $\mathrm{Bcl}-2$ expression, followed by gastric cell apoptosis. H. felis infection of INS-GAS mice led to increased apoptosis and the development of atrophy, whereas treatment with either YF476 and/or loxtidine strongly inhibited both apoptosis and atrophy. In vitro studies with Fas-expressing RGM1 cells showed that gastrin stimulation alone directly induced apoptosis via gastrin/CCK-2 receptor and synergized with FasL stimulation. These results indicate that gastrin can induce apoptosis in gastric epithelial cells and contribute to the development of gastric carcinogenesis.
\end{abstract}

Laboratory Investigation (2006) 86, 1037-1051. doi:10.1038/labinvest.3700462; published online 7 August 2006

Keywords: gastrin; apoptosis; atrophy; gastrin/CCK-2 receptor; histamine $\mathrm{H}-2$ receptor

Chronic infection with Helicobacter pylori is the strongest known risk factor for the development of gastric cancer, ${ }^{1,2}$ which arises through a multistep process leading from superficial gastritis to atrophy, metaplasia and eventually cancer. ${ }^{2,3}$ Chronic infection with $H$. pylori is associated with increases in serum gastrin-17 levels ${ }^{4}$ and while such hypergastrinemia precedes the development of atrophy and cancer, its pathogenic role has not been well defined. ${ }^{5}$

Gastrin released from antral G cells is generally viewed as the major physiologic regulator of gastric acid secretion and growth via the gastrin/cholecystokinin-2 (CCK-2) receptor. ${ }^{6}$ Hypergastrinemia can

Correspondence: Dr TC Wang, MD, Division of Digestive and Liver Disease, Department of Medicine, Columbia University, College of Physicians and Surgeons, 630 West 168th Street, Box 83, New York, NY 10032, USA.

E-mail: tcw21@columbia.edu

Received 3 August 2005; revised 9 June 2006; accepted 20 June 2006; published online 7 August 2006 be caused by a variety of pathological conditions and has been considered a possible contributor to gastrointestinal carcinogenesis. ${ }^{6,7}$ We have reported that hypergastrinemic transgenic mice (INS-GAS) show increased gastric atrophy, which is accelerated by Helicobacter infection ${ }^{8}$ and associated with increased gastrin and apoptosis. ${ }^{9}$ In addition, an association between apoptosis and gastrin has been observed in the hypergastrinemic rodent (Mastomys) model. ${ }^{10}$ In view of these observations, we hypothesized that an increased gastrin level may directly contribute to gastric cell apoptosis through gastrin/CCK-2 receptors and eventually to the development of gastric atrophy and cancer.

The aim of this study was to examine gastrininduced apoptosis and atrophy in INS-GAS mice of various ages. In addition, we studied apoptosis in gastrin deficient (GAS-KO) mice infused with gastrin-17, as well as the effects of gastrin/CCK-2 receptor and histamine $\mathrm{H} 2(\mathrm{H}-2)$ receptor antagonists in INS-GAS mice with and without Helicobacter felis (H. felis) infection. Finally, we examined 
the effect of gastrin on apoptosis in a nontransformed rat gastric cell line (RGM-1 cell). These studies suggest that gastrin can promote gastric carcinogenesis through induction of apoptosis.

\section{Materials and methods}

\section{Animals}

Male gastrin deficient (GAS-KO) mice ${ }^{11}$ and hypergastrinemic (INS-GAS) mice ${ }^{8}$ in which the serum amidated gastrin level is increased to $500 \mathrm{pmol} / \mathrm{ml}$, and wild-type FVB/N mice (Charles River Lab, Wilmington, MA, USA) were investigated. GAS-KO mice were used for G-17 infusion experiments, while INS-GAS mice were used for histological examination, $H$. felis infection, and treatment with gastrin/CCK-2 receptor antagonist YF476 and $\mathrm{H}-2$ receptor antagonist loxtidine. ${ }^{22}$ All of the mice were housed in a specific-pathogen-free environment and fed commercial pellets. All experiments were approved by the Animal Welfare Committee of the University of Massachusetts Medical School.

\section{Infusion of Gastrin-17 in Gastrin-Deficient Mice}

To examine the possible long-term effects of gastrin on gastric apoptosis, five GAS-KO mice at 2 months of age were given an infusion of phosphate-buffered saline (PBS) or gastrin-17 (G-17) at a dose of $10 \mathrm{nmol} \mathrm{kg} \mathrm{kg}^{-1}$ via subcutaneous Alzet osmotic minipumps (DURECT Corp., Cupertino, CA, USA) for 8 weeks. G-17 administered in this way has been shown to produce highly increased serum gastrin levels in mice. ${ }^{13}$ The mice were necropsied, at which time serum was collected for measurement of gastrin levels by the human gastrin G17 immunoassay kit (R\&D Systems, Minneapolis, MN, USA) according to the manufacturer's instructions. The optical density in each well was measured using a microplate reader Multiskan EX (Thermo, Waltham, MA, USA) with a wavelength of $405 \mathrm{~nm}$ as well as $620 \mathrm{~nm}$ for correction. The stomach was collected for histological examination and Western blotting. The thickness of the corpus was measured and parietal cell density was quantified.

\section{Western Blotting}

Stomachs from 2-month-old and 12-month-old male INS-GAS mice and GAS-KO mice that had been infused with G-17 for 8 weeks were homogenized and lysed in RIPA buffer $(150 \mathrm{mM} \mathrm{NaCl}, 1 \%$ Nonidet P-40, $0.5 \%$ sodium deoxycholate, $0.1 \%$ SDS, $50 \mathrm{mM}$ Tris-HCl, $\mathrm{pH} 7.4$, and EDTA $5 \mathrm{mM}$ ). We disassociated $100 \mu \mathrm{g}$ of proteins from each preparation by adding $30 \mu \mathrm{l}$ of $2 \times$ SDS sample buffer and boiling for $5 \mathrm{~min}$. These samples were subjected to electrophoresis in 4-20\% Tris-Glycine gels (Invitro- gen, Carlsbad, CA, USA). The proteins were detected by Western blot using anti-cleaved caspase-3 antibody (1:1000, Cell Signaling Technology, Danvers, MA, USA); anti-Bax and anti-Bcl-2 antibodies (1:1000, eBioscience, San Diego, CA, USA); anti-H $+\mathrm{K}+$ ATPase $\beta$-subunit antibody (1:2000, Affinity BioReagents, Golden, CO, USA); and anti- $\alpha$ tubulin antibody (1:2000, Oncogene, San Diego, CA, USA).

\section{H. felis Infection and Long-Term Treatment of Gastrin/CCK-2 Receptor and H-2 Receptor Antagonists in INS-GAS Mice}

INS-GAS mice at the age of 6-8 weeks were divided into $H$. felis-infected (ATCC 49179) ${ }^{8}$ and uninfected groups (15 or 20 mice per group). Four mice from each group were necropsied after infection with $H$. felis for 1 month for the examination of apoptosis in gastric glandular cells. Others were treated for 6 months with (a) gastrin/CCK-2 receptor antagonist YF476 (a kind gift from Dr Keiji Miyata and Dr Hidenobu Yuki, Yamanouchi Pharmaceutical Co. Ltd., Tsukuba, Japan), (b) histamine $\mathrm{H}-2$ receptor antagonist loxtidine manufactured by GlaxoSmithKline Inc. (synthesized by Research Triangle Park, NC, USA, and a generous gift of Professor Duan Chen, Norwegian University of Science \& Technology, Norway and Professor Rolf Hakanson, Lund University, Sweden) or (c) both agents. The YF476 was dissolved in polyethylene glycol 300 (Sigma, St Louis, MO, USA) and subcutaneously injected weekly at a dose of $40 \mathrm{mg} / \mathrm{kg}(=80 \mu \mathrm{mole} / \mathrm{kg})$. The loxtidine was dissolved in drinking water at a dose of $0.5 \mathrm{~g} / \mathrm{l}$. The efficiency of treatments was confirmed by markedly increased serum gastrin levels. ${ }^{12}$ Histological changes in the stomachs were examined after treatment for 6 months.

\section{In Vitro Apoptosis Analysis of RGM1-Fas Cells}

Rat gastric normal epithelial cell line RGM1 cells were stably transfected with human Fas antigen (RGM1-Fas cells); ${ }^{14}$ the expression of gastrin/ CCK-2 receptor at a low level in RGM1 cells was confirmed (Ai et al, unpublished data). The cells were cultured in DMEM containing 20\% FBS at $37^{\circ} \mathrm{C}$ with $5 \% \mathrm{CO}_{2}$ and $95 \%$ air in a humidified incubator. Cells were plated in six-well plates at a density of $1 \times 10^{5}$ cells/well and incubated for 3 days. After $24 \mathrm{~h}$ of serum starvation, the cells were stimulated with G-17 at a dose of $10^{-7} \mathrm{M}$, human FasL at a dose of $50 \mathrm{ng} / \mathrm{ml}$, or both, for $24 \mathrm{~h}$. To determine the specificity of apoptosis, a pan-caspase inhibitor VI (Calbiochem, San Diego, CA, USA) was added to the culture medium $30 \mathrm{~min}$ before gastrin treatment.

To examine the sufficiency of gastrin in inducing cell apoptosis, cleared supernatant of RGM1 culture after $24 \mathrm{~h}$ of $10^{-7} \mathrm{M}$ gastrin treatment (conditioned 
medium) was used to stimulate starved RGM1 cells with and without $30 \mathrm{~min}$ of pretreatment with CCK2 receptor antagonist (YF476, $\left.10^{-6} \mathrm{M}\right)$. Detection of apoptosis in RGM1-Fas cells was carried out using Annexin V-FITC Apoptosis Detection Kit (Oncogene Sci., Cambridge, MA, USA), followed by fluorescence-activated cell sorter (FACS) analysis ${ }^{15}$ at the core flow cytometry facility of the University of Massachusetts Medical School and the Columbia University FACS Facility according to the manufacturer's instructions. Each experiment was repeated three times; average values were used to show the percentage of cells in late apoptosis.

\section{Stomach Histology and Immunohistochemistry}

Stomach biopsies from wild-type FVB/N, GAS-KO, and INS-GAS mice were prepared and embedded in paraffin. ${ }^{9}$ Sections were cut at $4 \mu \mathrm{m}$, then stained with hematoxylin and eosin ( $\mathrm{H} \& \mathrm{E})$. Immunohistochemistry was performed with LSAB-2 system-HRP kits (Dako, Carpinteria, CA, USA) according to the manufacturer's instructions. ${ }^{9}$ Antigen retrieval was achieved by boiling sections for $15 \mathrm{~min}$ in $0.01 \mathrm{M}$ citrate buffer, pH 6.0. We used Bax antibody (1:70, Santa Cruz Inc., Santa Cruz, CA, USA) and Bcl-2 antibody (1:70, Santa Cruz Inc., Santa Cruz, CA, USA) to examine the expression of $\mathrm{Bcl}-2$ family proteins; a rabbit monoclonal antibody specific for cleaved (activated) caspase-3 antibody (1:100, Cell Signaling Technology, Danvers, MA, USA) to evaluate apoptosis in gastric cells; and anti-human Ki-67 monoclonal antibody (1:70, BD PharMingen, San Diego, CA, USA) to assess gastric cell proliferation. We used $\mathrm{H}+\mathrm{K}+$-ATPase $\beta$-subunit antibody to stain parietal cells $(1: 2000$, Affinity Bioreagents, Golden, CO, USA) and fluorescence (FITC)-labeled Ulex europaeus agglutinine I lectin (1:400; Sigma, St Louis, MO, USA) to show pit cells (also called mucus cells). We used 3-amino-9-ethylcarbazole (AEC; Vector Laboratories, Burlingame, CA, USA) as chromogen, except for FITC-labeled lectin staining. These slides were counterstained with Mayer's hematoxylin.

\section{Single and Double Staining to Identify Gastric Cell Apoptosis}

Terminal dUTP nick-end labeling (TUNEL) staining $^{16,17}$ was performed with the peroxidase-labeled TUNEL kit (Calbiochem., San Diego, CA, USA) according to the manufacturer's instructions to identify apoptosis in gastric cells. Double immunofluorescence staining with activated caspase-3 and $\mathrm{H}+\mathrm{K}+$-ATPase antibodies was carried out as previously described combined with fluorescence (FITC)-conjugated or tetramethylrhodamine isothiocyanate (TRITC)-conjugated secondary IgG antibodies (1:100; Jackson ImmunoRearch Lab., West Grove, PA, USA) ${ }^{9,18}$ to show increased proapoptotic signals in parietal cells. Double staining with TUNEL and $\mathrm{H}+\mathrm{K}+$-ATPase antibody was used to illustrate apoptotic parietal cells. In brief, following TUNEL staining (AEC was used as chromogen, red color; Vector Laboratories, Burlingame, CA, USA), slides were washed with PBS-Trixton-100 $10 \mathrm{~min} \times 3$, then incubated with mouse anti$\mathrm{H}+\mathrm{K}+$-ATPase $\beta$-subunit antibody (1:2000; Affinity Bioreagents, Golden, CO, USA) for $2 \mathrm{~h}$ at room temperature. Slides were developed by ABC kit (Vector Laboratories, Burlingame, CA, USA) and 3,3' diaminobenzidine (DAB; yellow color; Vector Laboratories, Burlingame, CA, USA) was used as chromogen (Vector Laboratories, Burlingame, CA, USA). These slides were slight counterstained with Mayer's hematoxylin.

\section{Morphometric Analysis}

Well-oriented sections were examined with a light microscope (CX31, Olympus Optical Co., LTD, New York, USA). Immunofluorescence staining was observed by confocal microscopy (LSM-510 meta, Carl Zeiss, Jena, Germany). Immunoreactive cells were counted in at least five randomly selected visual fields (objective, $\times 20$; eyepiece, $\times 10$; visual field diameter, $1.85 \mathrm{~mm})$. Apoptotic cells with caspase-3 immunoreactivity and TUNEL positive cells were expressed as number per field; parietal cell density was expressed as number per gland. The fundic thickness in GAS-KO mice after 8-weeks of G-17 infusion and in INS-GAS mice was measured using a micro-ruler. The results were expressed as millimeters (mm).

\section{Statistical Analysis}

The results were expressed as mean \pm s.e.m. unless otherwise stated. The Student's $t$-test or MannWhitney test and one-way ANOVA were used to evaluate statistical significance. Values of $P<0.05$ or $P<0.01$ were considered significant.

\section{Results}

\section{Hypergastrinemia is Associated with Altered Expression of Bcl-2 Family Proteins and Increased Apoptosis}

To determine whether Bcl-2 family proteins were involved in the development of gastrin-induced apoptosis, we examined the antiapoptotic protein Bcl-2 and the proapoptotic protein Bax in the stomachs of INS-GAS mice and G-17-infused gastrin-deficient (GAS-KO) mice using immunohistochemistry. In 2-month-old wild-type mice, Bax and Bcl-2 proteins appeared evenly expressed in gastric glandular cells (Figure 1a, e). In INS-GAS mice of the same ages, the expression of Bax was substantially increased (Figure 1c), whereas the expression 
of Bcl-2 was lower than that in wild-type mice (Figure 1g). At 12 months of age, neither Bax nor Bcl-2 expression was changed in wild-type mice (Figure 1b for Bax; Figure 1f for Bcl-2). However, INS-GAS mice showed more prominent changes. Bax expression was further increased and detectable in most gastric cell types (Figure 1d), whereas Bcl-2 was difficult to detect in most glandular regions (Figure 1h). In GAS-KO mice, G-17 infusion for 8 weeks induced notably increased serum gastrin levels $(521 \pm 129 \mathrm{pM}$ vs undetected serum gastrin in PBS-infused GAS-KO mice). The expression patterns of Bax and Bcl-2 proteins were similar to those observed in INS-GAS mice. Bax expression was higher and Bcl-2 was lower in the glandular regions (Figure 2b, d) of these animals as compared with the levels in PBS-infused GAS-KO mice (Figure 2a, c).
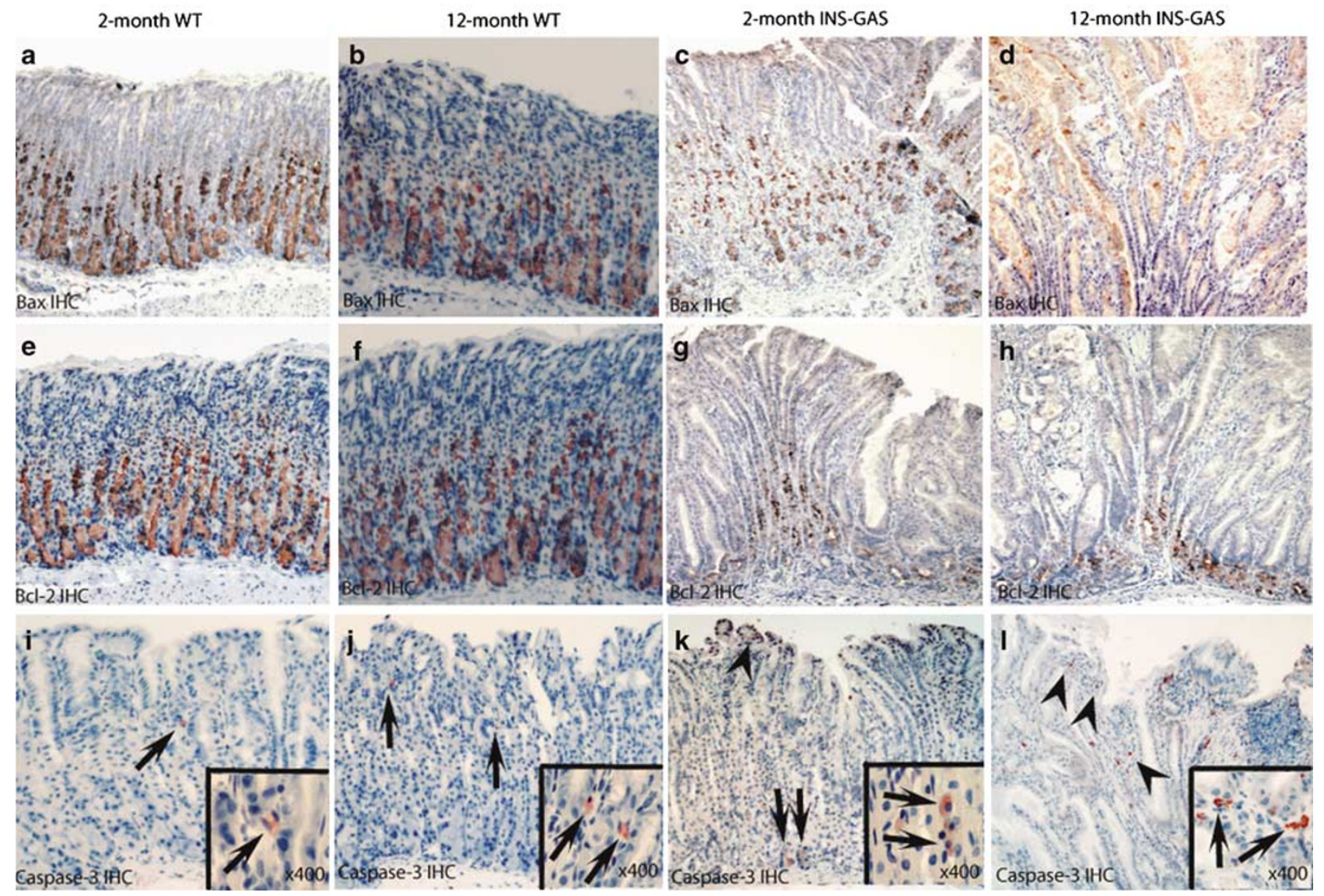

Figure 1 Immunohistochemical examination of Bcl-2 family protein expression and apoptosis (labeled by activated caspase-3 immunoreactivity) in the stomachs of INS-GAS mice at different ages. Bcl-2 family protein expression in INS-GAS mice: Compared with wild-type (WT) background FVB/N mice at the ages of 2 and 12 months (Bax: (a) 2 months; (b) 12 months. Bcl-2: (e) 2 months; (f) 12 months), Bax protein expression gradually increased (c) 2 months; (d) 12 months), while Bcl-2 expression decreased (g) 2 months; (h) 12 months) in INS-GAS mice. Gastric cell apoptosis in INS-GAS mice: Compared with WT FVB/N mice at the ages of 2 and 12 months (i) and inserted image, 2 months; (j) and inserted image, 12 months), INS-GAS mice at the age of 2 months had a higher apoptosis rate in the basal part gastric glandular (arrows in $\mathbf{k}$ and inserted image) and surface cells (arrow heads in $\mathbf{k}$ ). The apoptosis rate remained high on mucosal surface cells (arrow heads in l) and mensenchymal cells (inserted image in l) at the age of 12 months after parietal cells were lost (l). Counterstained with hematoxylin (original magnification $\times 100$, unless otherwise stated in images).

Figure 2 Immunhistochemical examination of $B c l-2$ family protein expressions and apoptosis (labeled by activated caspase-3 immunoreactivity) in the fundus of stomachs of 8-week G-17 infused GAS-KO mice. Bcl-2 family protein expression examination in GAS-KO mice: this revealed increased Bax protein expression and decreased Bcl-2 protein expression in the middle and lower thirds of gastric glands in G-17 infused GAS-KO mice ((b) Bax; (d) Bcl-2) as compared with expression in PBS-infused GAS-KO mice ((a) Bax; (c) Bcl-2). Gastric cell apoptosis in GAS-KO mice: Compared to PBS-infused control GAS-KO mice (e), 8-week G-17 infusion resulted in an increased number of apoptotic cells in the same area as the Bax expression region (f). Some glandular cells showed colocalization of caspase-3 (red) and $\mathrm{H}+\mathrm{K}+$-ATPase (green) immunoreactivity in parietal cells ((g) for $\mathrm{H}+\mathrm{K}+$-ATPase immunoreactivity (green); (h) for caspase-3 immunoreactivity (red) and (i) for $\mathrm{H}+\mathrm{K}+$-ATPase/caspae-3 double immunoreactivity). TUNEL staining (red) showed apoptosis in glandular cells ( $\mathrm{j}$ ) and TUNEL (red)/H $+\mathrm{K}+$-ATPase (yellow) double staining confirmed some apoptotic glandular cells to be parietal cells (arrow head in inserted image). Counterstained with hematoxylin (original magnification $\times 100$, unless otherwise stated in images). 
Double immunofluorescence staining with antibodies against activated caspase- 3 and $\mathrm{H}+\mathrm{K}+$ ATPase clearly demonstrated that most of those apoptotic glandular cells were parietal cells (Figure $2 \mathrm{~g}$ for $\mathrm{H}+\mathrm{K}+$-ATPase immunoreactivity; Figure $2 \mathrm{~h}$ for caspase-3 immunoreactivity; Figure $2 \mathrm{i}$ for

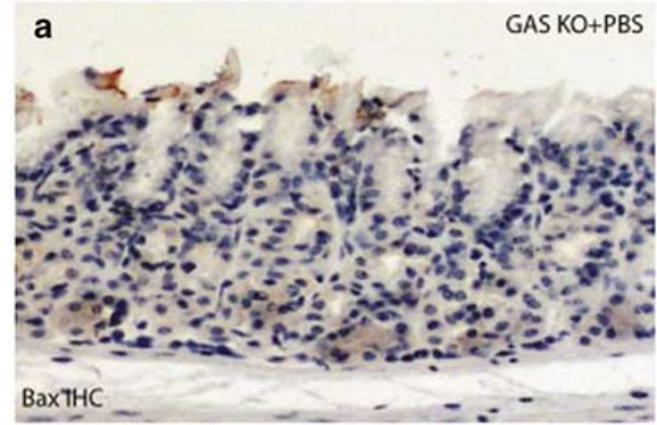

b

GAS KO+G-17
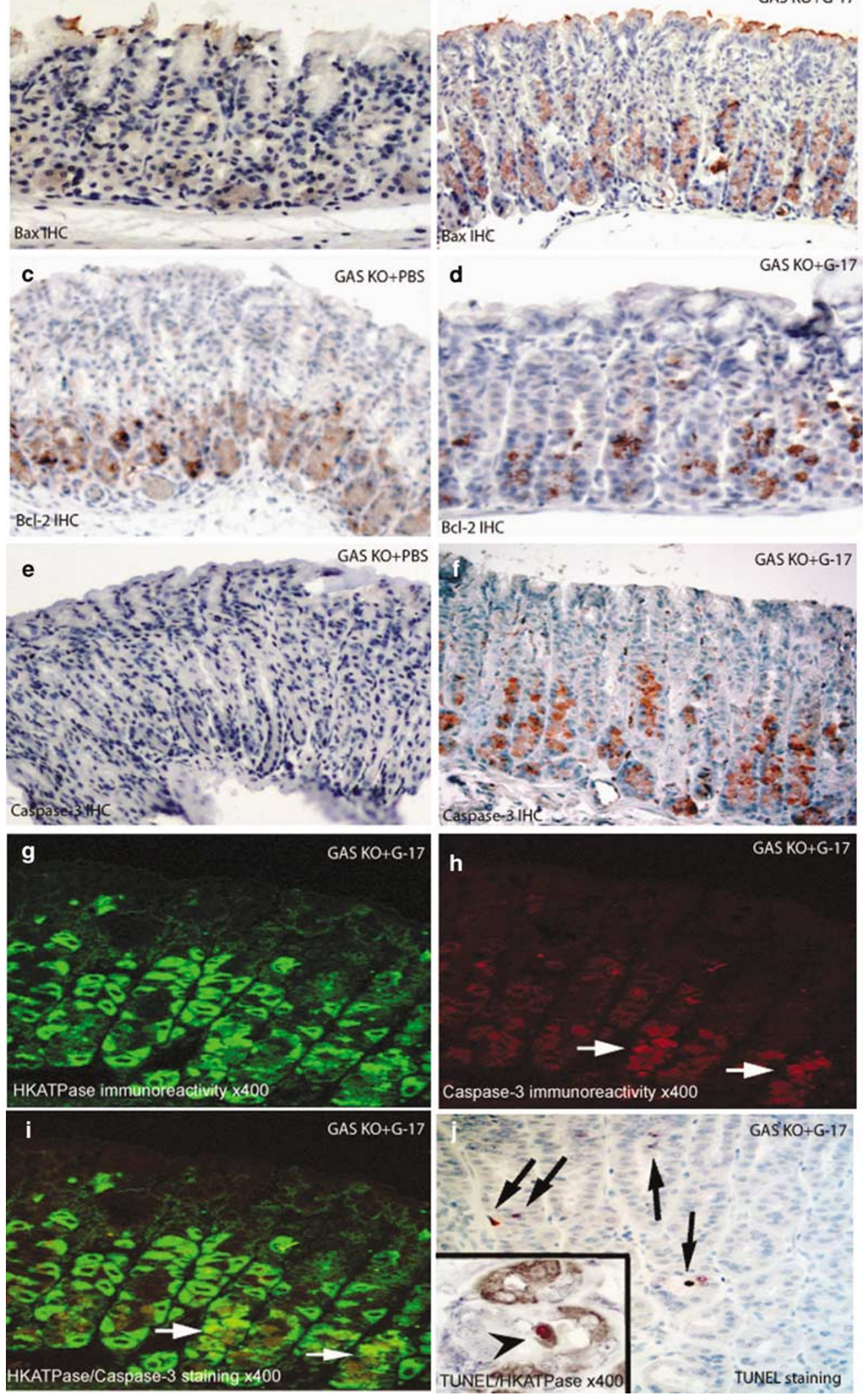
$\mathrm{H}+\mathrm{K}+$-ATPase/caspase-3 double immunoreactivity). TUNEL staining also showed increased apoptotic cells inside gastric glands (Figure 2j) and that some apoptotic cells in glands were parietal cells (inserted image in Figure 2j). The density of apoptotic parietal cells in G-17 infused GAS KO mice was increased as compared to PBS infused GAS KO mice (4.0/field vs 0.1/field). To further confirm the effects of gastrin on apoptosis-related proteins, changes in activated caspase-3, Bax, Bcl-2, and $\mathrm{H}+\mathrm{K}+$-ATPase proteins were quantified by Western blots performed on stomach tissue of GAS-KO mice infused with G-17 for 8 weeks and INS-GAS mice at the ages of 2 and 12 months. This demonstrated that G-17 infusion for 8 weeks resulted in increased protein expression of activated caspase-3 and Bax, but decreased expression of Bcl-2 in the stomach (Figure 3a). INS-GAS mice (2-month-old) had increased Bax and caspase-3, but decreased Bcl-2. In 12-month-old INS-GAS mice, Bax and caspase-3 remained elevated, while Bcl-2 was further reduced (Figure $3 \mathrm{~b}$ ). The expression of $\mathrm{H}+\mathrm{K}+$-ATPase was increased in G-17 infused GAS-KO mice as compared to control (PBS infused) mice, but gradually declined in INS-GAS mice with increasing age (Figure $3 \mathrm{~b}$ ).

In parallel with the changes in the expression pattern of Bcl-2 family proteins, hypergastrinemia was associated with alterations in the localization of gastric apoptotic cells. In 2- and 12-month-old wildtype FVB/N mice, apoptotic parietal cells were only occasionally observed in the gastric fundus (Figure $1 \mathrm{i}$ and inserted image, Figure $1 \mathrm{j}$ and inserted image). In 2-month-old INS-GAS mice, the number of apoptotic cells labeled by caspase-3 immunoreactivity was increased in both basal part of gastric glandular cells (arrows in Figure 1k and inserted image) and surface cells (arrow heads in Figure 1k), while 12-month-old INS-GAS mice had an increased apoptosis in gastric surface cells (arrow heads in Figure 1l) and stromal cells (inserted image in Figure 11). As demonstrated by double immunofluorescence staining with activated caspase-3 and $\mathrm{H}+\mathrm{K}+$-ATPase antibodies, most of the glandular apoptotic cells were parietal cells (Figure 4a for $\mathrm{H}+\mathrm{K}+$-ATPase immunoreactivity, Figure $4 \mathrm{~b}$ for caspase-3 immunoreactivity and Figure 4c for $\mathrm{H}+\mathrm{K}+$-ATPase/caspae-3 double immunoreactivity). TUNEL staining confirmed that some of these cells had reached the later stages of apoptosis within gastric glands (Figure 4d) and gastric pits (Figure 4d and inserted image). In addition, some apoptotic glandular cells were shown by double staining with TUNEL and $\mathrm{H}+\mathrm{K}+$-ATPase antibody (Figure $4 \mathrm{e}$ for TUNEL staining and Figure $4 \mathrm{f}$ for TUNEL/H $+\mathrm{K}+-$

\section{a}

cleaved caspase-3

\section{Bax}

$\mathrm{Bcl}-2$

HK-ATPase $\beta$

$\alpha$-tubulin

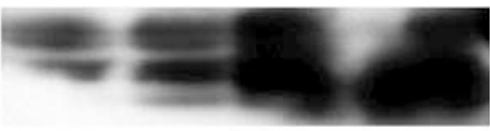

b

cleaved caspase-3

Bax

$\mathrm{Bcl}-2$
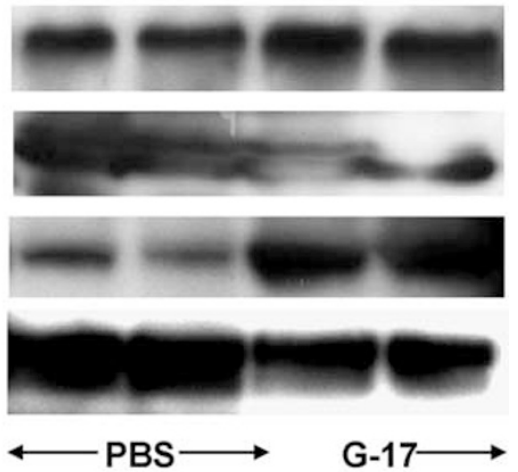

G-17

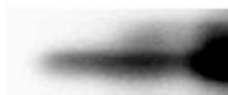

HK-ATPase $\beta$

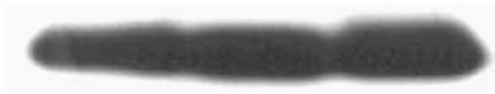

$\alpha$-tubulin
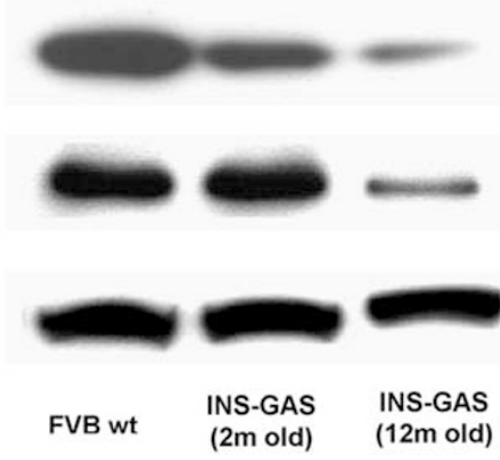

Figure 3 Examination of apoptosis-related protein expression by Western blots of stomach tissue of GAS-KO mice infused with G-17 for 8 weeks and INS-GAS mice at the ages of 2 and 12 months. (a) Western blotting of gastric lysate of gastrin-deficient (GAS-KO) mice with G-17 or PBS infusion for 8 weeks. As compared to control mice (left two with PBS-infused) GAS-KO mice infused with G-17 (right two mice) for 8 weeks had increased expression of cleaved caspase- 3 , bax and $\mathrm{H}+\mathrm{K}+$-ATPase beta proteins, while bcl-2 protein was decreased. (b) Western blotting of gastric lysates from hypergastrinemic (INS-GAS) mice of 2 and 12 months old. As compared to control FVB/N mice, INS-GAS mice between the ages of 2-12 months had increased expression of cleaved caspase-3 and Bax, but decreased expression of Bcl-2 and $\mathrm{H}+\mathrm{K}+$-ATPase.

Figure 4 Examination of apoptosis in parietal cells labeled by $\mathrm{H}+\mathrm{K}+$-ATPase, caspase- 3 and TUNEL in the fundus of INS-GAS mice at the ages of 2 and 12 months. Double immunofluorescence staining demonstrated that most caspase-3 immunoreactive (red) glandular cells were colocalized with $\mathrm{H}+\mathrm{K}+$-ATPase immunoreactivity (green) ((a) for $\mathrm{H}+\mathrm{K}+$-ATPase immunoreactivity; (b) for capase-3 immunoreactivity and (c) for $\mathrm{H}+\mathrm{K}+$-ATPase/caspase-3 double immunoreactivity) in INS-GAS mice at 2 months. TUNEL staining (red) showed that increased apoptosis inside glands (arrows in d) and epithelium cells (arrow heads in d and inserted image), double TUNEL/ $\mathrm{H}+\mathrm{K}+$-ATPase staining confirmed that TUNEL-positive glandular cells (e) were parietal cells (f). Furthermore, images for $\mathrm{H}+\mathrm{K}+$ ATPase immunostaining of stomach section show that the parietal cell number in INS-GAS mice at 12 months (h) was clearly reduced as compared to INS-GAS mice at 2 months (g). Counterstained with hematoxylin except immunofluorescence staining (original magnification $\times 100$, unless otherwise stated in images). 
ATPase double staining, respectively) to be parietal cells. As compared with 2-month-old INS-GAS mice (Figure 4g), 12-month-old INS-GAS mice character- istically had significant severe gastric atrophy and marked distortion of the fundic glandular architecture (Figure 4h). Consequently, parietal cells were
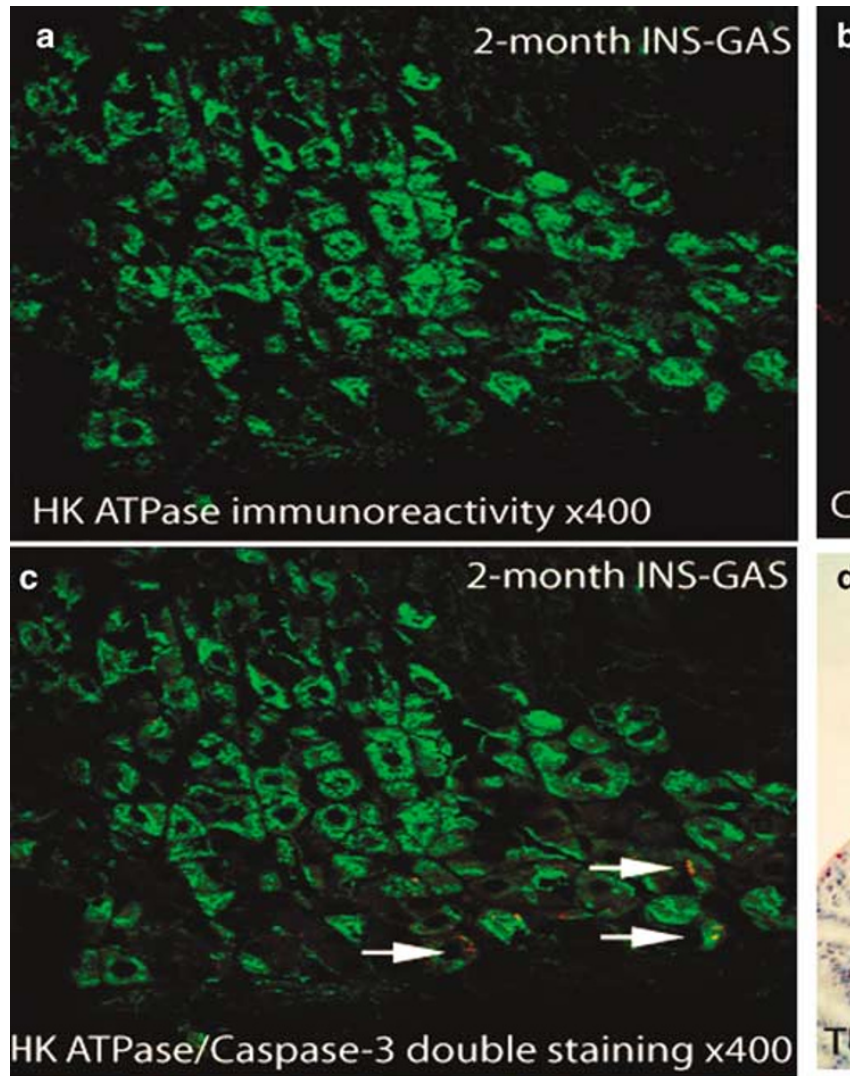

Caspase -3 immunoreactivity $\times 400$
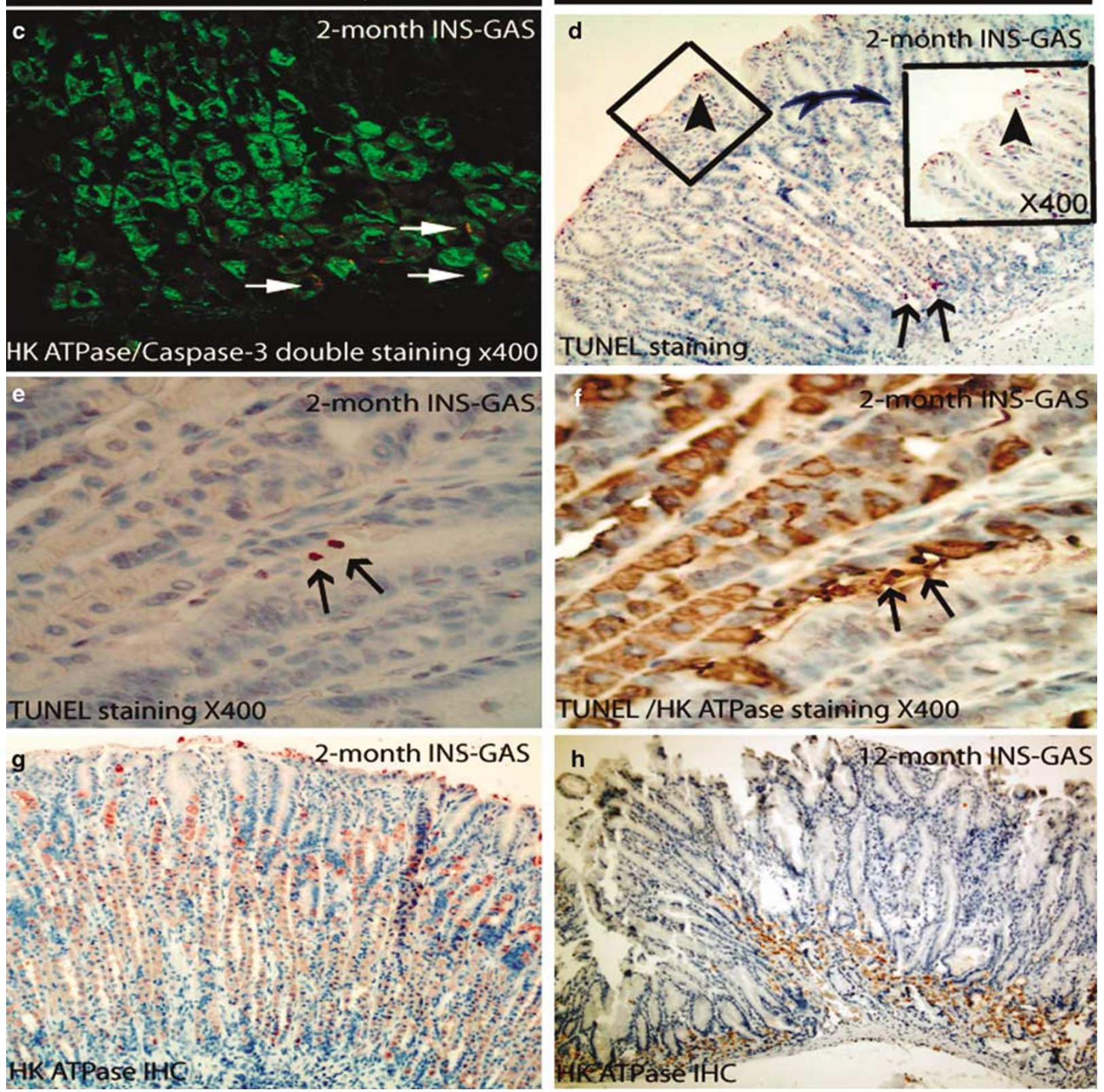
nearly $50 \%$ decreased (7 8/gland vs $17 /$ gland at the age of 2 months), ${ }^{9}$ and apoptosis was present primarily in surface mucous cells (Figure 1l), as well as in extraglandular mesenchymal cells (inserted image in Figure 11).

In GAS-KO mice, 8 weeks of G-17 infusion resulted in a markedly increased number of apoptotic parietal cells (Figure 2j). However, the total number of parietal cells and the overall fundic mucosal thickness were increased only slightly (Figure 5a and b, $P>0.05$ as compared with control mice). Considering that $\mathrm{H}+\mathrm{K}+$-ATPase protein was upregulated in G-17 infused GAS-KO mice (Figure 3a), this might indicate a higher $\mathrm{H}+\mathrm{K}+$-ATPase amount in each parietal cell. However, previous studies have found that in GAS-KO mice 2-week G-17 infusion resulted in significantly increased numbers of parietal cells and greater fundic mucosal thickness, ${ }^{13}$ suggesting that continuing G-17 infusion beyond 2 weeks would lead to increased apoptosis and a gradual decline in parietal cell numbers.

\section{Long-Term $H$. felis Infection Results in Worsening Hypergastrinemia and Increased Gastric Apoptosis}

The preceding results indicate that moderate hypergastrinemia in mice was associated with increased apoptosis of glandular cells and, to some extent, mesenchymal and surface mucous cells. Overall, INS-GAS mice had $45 \pm 3$ apoptotic cells/visual field, whereas wild-type mice had one to two apoptotic cells/visual field, which is consistent with our earlier report. ${ }^{9}$ To address the role of more severe hypergastrinemia, we inoculated INS-GAS mice with $H$. felis, which has been shown to lead rapidly to relatively severe hypergastrinemia. ${ }^{8}$

In INS-GAS mice, TUNEL assays revealed that 1-month $H$. felis infection resulted in an increased glandular apoptosis (Figure 6b and c) as compared to noninfected mice (Figure 6a). H. felis infection of INS-GAS mice for 6 months led to serum gastrin levels over $500 \mathrm{pmol} / \mathrm{l}$ and increased gastric apoptotic cells in the range of $127 \pm 7 /$ visual field $(P<0.01$ as compared to INS-GAS mice without $H$. felis infection) (Figure 7). After 6 months of infection, INS-GAS mice had advanced gastric atrophy with few, if any, parietal cells. Consequently, at this time point, most of the apoptotic cells were mesenchymal cells under surface epithelium
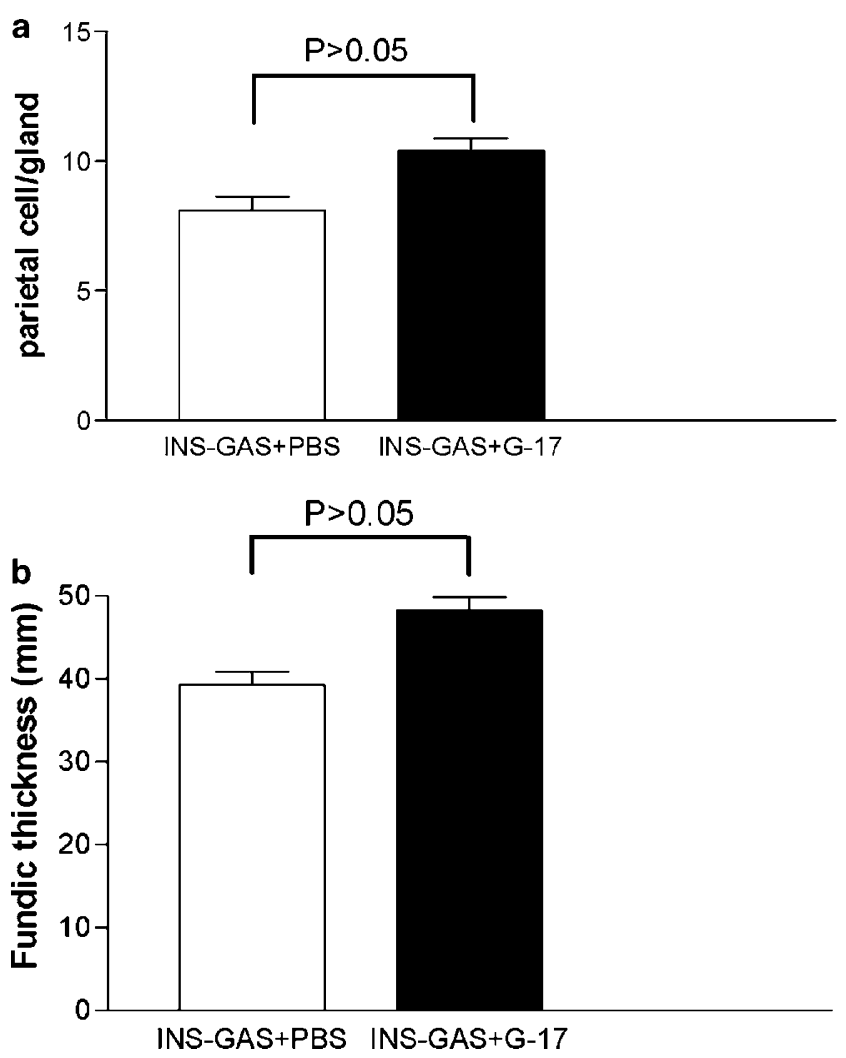

Figure 5 Measurements of parietal cell number per gland and fundic mucosal thickness $(\mathrm{mm})$ in GAS-KO mice infused for 8 weeks with G-17. G-17 infusion induced only a nonstatistical difference in the increases in numbers of parietal cells. (a) (black bar, $P>0.05$, significantly different from PBS-infused GAS-KO mice, white bar); fundic mucosal thickness increased (b black bar, $P>0.05$, significantly different from PBS-infused GAS-KO mice, white bar).

(Figure 6d), extraglandular mesenchymal cells (Figure 6e) and infiltrated immune cells (Figure 6f) rather than parietal cells. Furthermore, H. felis infection for 6 months resulted in marked hypertrophy and severe dysplasia as compared with the state of uninfected INS-GAS mice (Table 1). Immunohistochemical studies using FITC-labeled lectin confirmed that gastric pit cell density was increased in hypertrophic regions of the stomachs of wild-type mice after 6 months of $H$. felis infection (Figure 8b) as compared with the same features in uninfected wild-type mice (Figure 8a). Increased pit cell density was also observed in hypergastrinemic INS-GAS mice (Figure 8c), but this change was more

Figure 6 Immunohistochemical examination of gastric apoptosis (labeled by TUNEL or activated caspase-3 immunoreactivity) and proliferation rate (labeled by Ki-67 immunoreactivity) in INS-GAS mice infected with $H$. felis for 1 and 6 months. In INS-GAS mice, 1 month $H$. felis infection resulted in an increased apoptosis in gastric glands of INS-GAS mice (b) as compared with noninfected mice (a); some of the apoptotic glandular cells appeared to be parietal cells (arrows in b and c). At 6-month $H$. felis infection elicited accelerated atrophy and enlarged foveolar regions. Apoptosis was not detected in parietal cells in most regions, but there was increased apoptosis in gastric cells of the mesenchymal cells under surface epithelium (d), extraglandular mesenchymal region (e) and infiltrated immune cells (f). Apoptosis was strongly inhibited by treating mice with YF476 (g) and loxtidine (h) or combination of both (i). At 6-month H. felis infection also resulted in an increased proliferation rate in most gastric cell types, including cells in foveolar regions (j). The proliferation rate was greatly decreased after YF476 (k) or loxtidine (l) treatment. Counterstained with hematoxylin (original magnification $\times 100$, unless otherwise stated in images). 

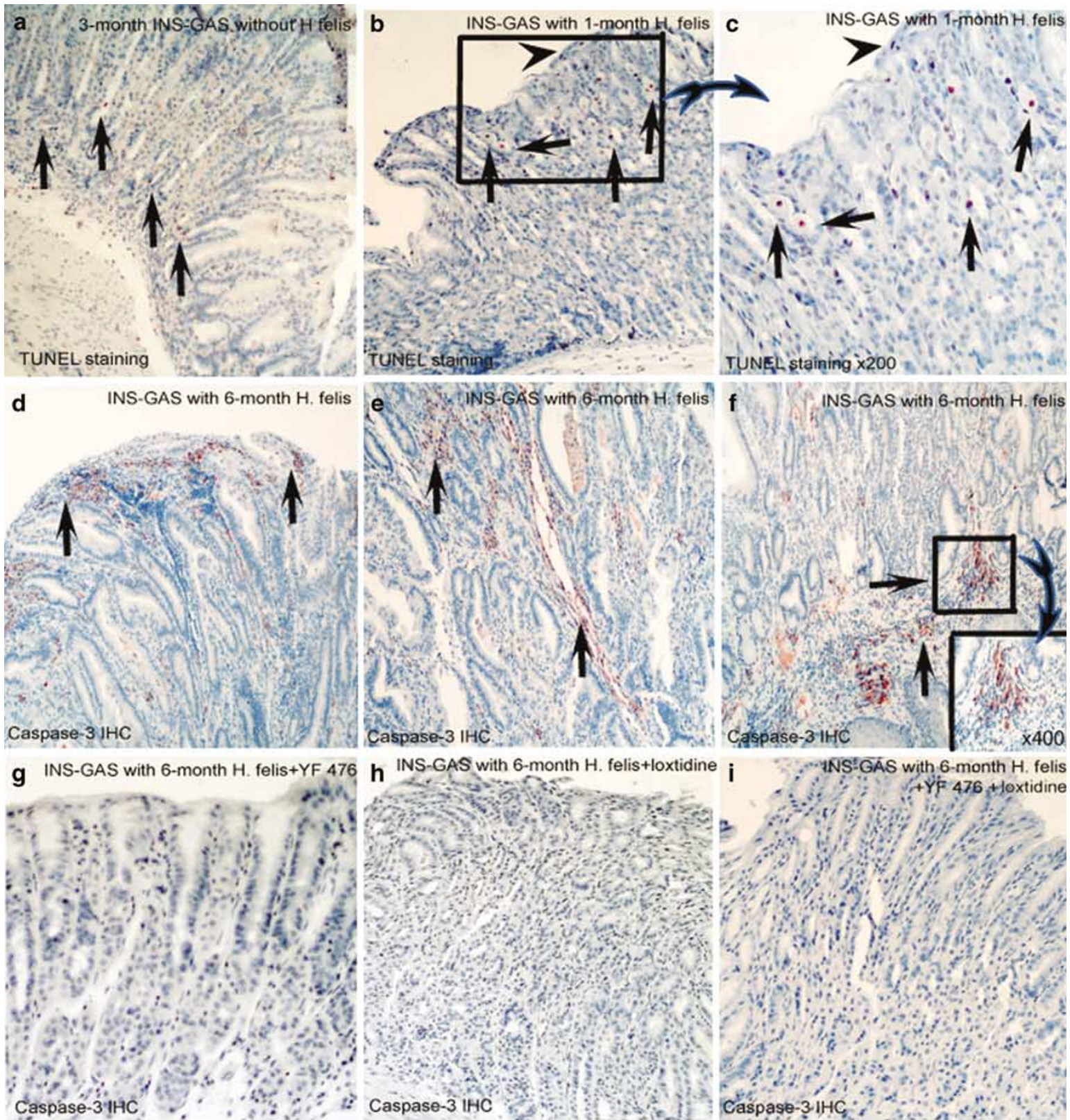

h INS-GAS with 6-month $\mathrm{H}$. felis+loxtidine
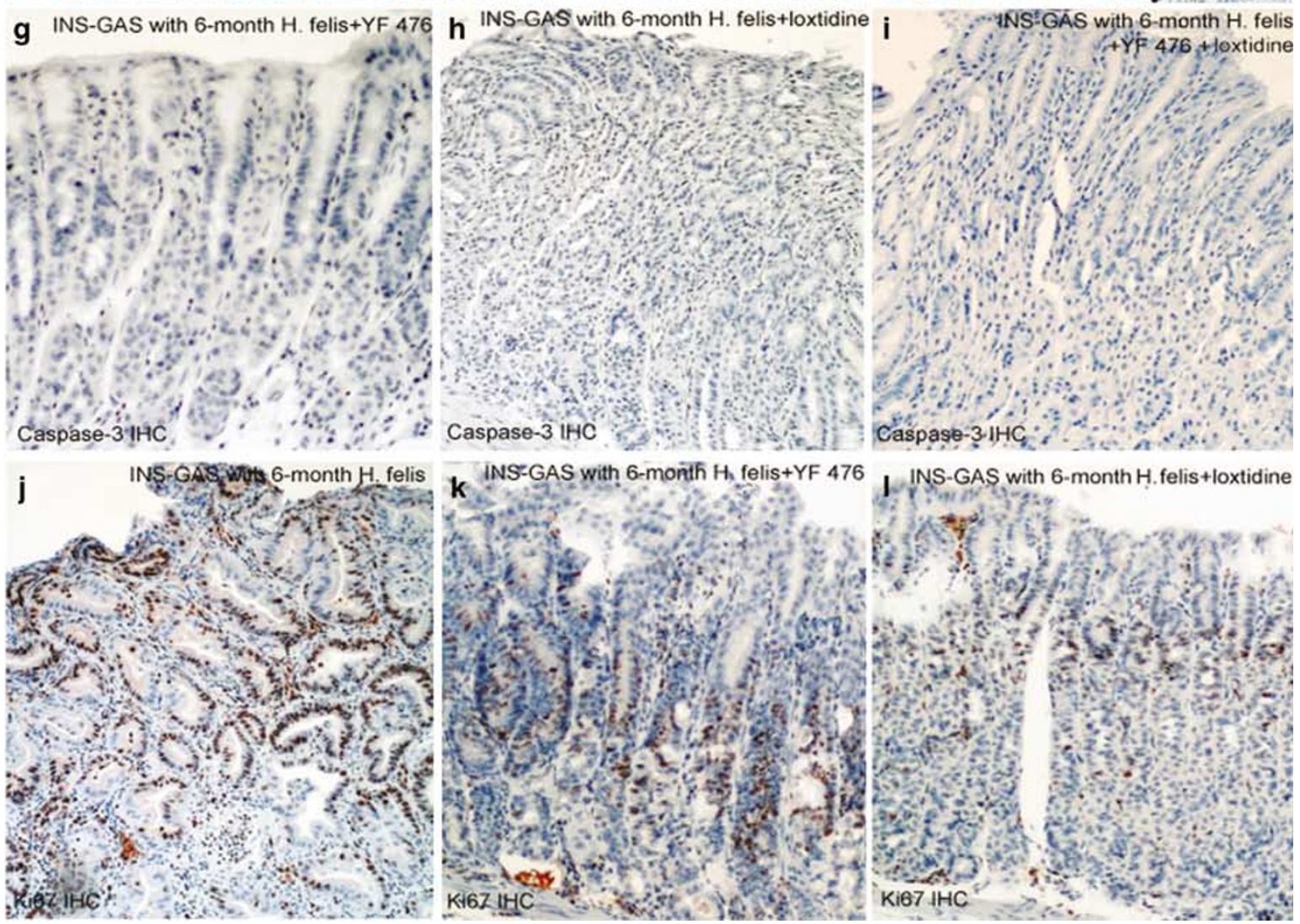


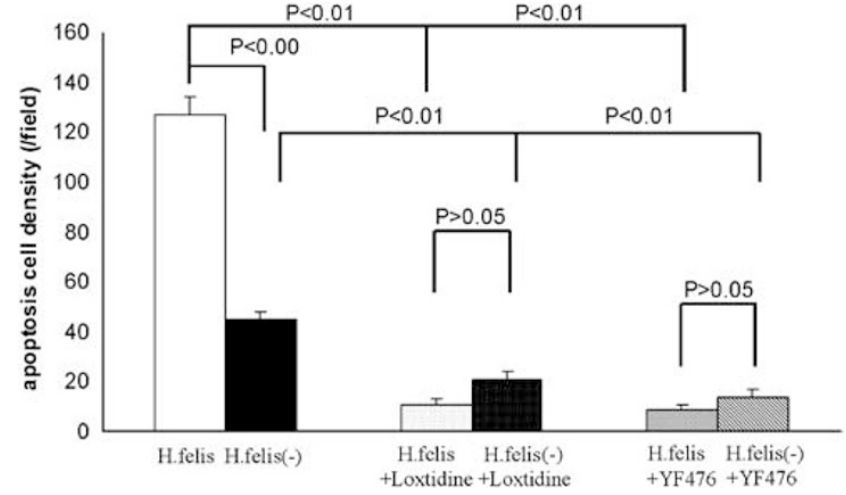

Figure 7 Counting of apoptotic gastric cell number in INS-GAS mice either uninfected or infected for 6 months with $H$. felis and treated with YF476 and/or loxtidine. As compared with the number of apoptotic gastric cells in INS-GAS mice without $H$. felis infection (black bar), those infected with $H$. felis for 6 months had a significantly increased number of apoptotic gastric cells (white bar, $P<0.01$ ). Treatment with YF476 and/or loxtidine significantly reduced the number of apoptotic gastric cells in INSGAS mice with $H$. felis infection (YF476: thin point bar; loxtidine: thin line bar. Both $P<0.01$, significantly different from those mice without treatment (white bar) or without $H$. felis infection (YF476 : black point bar; loxtidine: thick line bar). After treatment with either YF476 or loxtidine (both $P>0.05$ ), gastric apoptotic cell numbers did not differ in INS-GAS mice infected with $H$. felis infected and those that were not infected.

prominent in INS-GAS mice infected with $H$. felis (Figure 8d). Indeed, the cellular turnover rate was much higher in the hypertrophic foveolar regions of $H$. felis-infected mice, as demonstrated by the finding that these regions were characterized by increased apoptotic (Figure 6d) and proliferation rates (Figure 6j).

\section{Gastrin-Induced Apoptosis is Inhibited by Gastrin/ CCK-2 Receptor and H-2 Receptor Antagonists}

Recently, we have shown that treating $H$. felisinfected INS-GAS mice for 6 months with the gastrin/CCK-2 receptor antagonist YF476 or the $\mathrm{H}-2$ receptor antagonist loxtidine significantly inhibited gastric atrophy and the progression of cancer although increased serum gastrin levels to $\sim 1400$ and $\sim 800 \mathrm{pmol} / \mathrm{l}$, respectively. ${ }^{12}$ However, treatment for the same period (6 months) with the combination of YF476 and loxtidine, which increased serum gastrin levels to $\sim 1000 \mathrm{pmol} / \mathrm{l}$, also resulted in almost complete inhibition of gastric cancer. ${ }^{12}$ In the current study, we examined the effect on apoptotic rates of 6 months of treatment with YF476 and/or loxtidine in INS-GAS mice with
Table 1 Fundic mucosal thickness $(\mathrm{mm})$ in INS-GAS mice treated with YF476 and/or loxtidine

Fundic thickness (mm)

$\mathrm{FVB} / \mathrm{N}$

$50.63 \pm 5.87$

INS-GAS mice with $H$. felis infection

Non-treated

YF476

Loxtidine

YF476+loxtidine

$122.4 \pm 10.59^{a}$

$92.67 \pm 15.34^{\mathrm{b}, \mathrm{c}}$

$95.25+6.02^{\mathrm{b}, \mathrm{c}}$

$64.58 \pm 5.75^{\mathrm{b}, \mathrm{c}}$

INS-GAS mice without $H$. felis infection

Non-treated

YF476

Loxtidine

$92.25 \pm 6.65$

YF476+loxtidine

$63.88+4.40^{\mathrm{d}, \mathrm{e}}$

$57.78+5.88^{\mathrm{d}, \mathrm{e}}$

${ }^{\text {a }}$ Significant between $H$. felis infected INS-GAS mice and wild type mice $(P<0.01)$.

${ }^{\mathrm{b}}$ Significant between $H$. felis infected INS-GAS mice and untreated $H$. felis infected INS-GAS mice $(P<0.05)$.

${ }^{\mathrm{c}}$ Not significant among three treated groups $(P>0.05)$.

${ }^{\mathrm{d}}$ Significant between treated uninfected INS-GAS mice and nontreated uninfected INS-GAS mice $(P<0.05)$.

${ }^{\mathrm{e}}$ Not significant among three treated uninfected INS-GAS mice groups $(P>0.05)$

or without $H$. felis infection. Treatment with either drug resulted in a dramatic reduction in caspase-3labeled apoptotic cells (Figure 6g-i) and Ki-67labeled proliferating cells (Figure 6k and l), which suggests significant inhibition of both gastric apoptosis and proliferation. Enlarged foveolar regions and fundic mucosal thickness were also greatly reduced (Figure 8e-g and Table 1), although the difference in fundic thickness was not statistically significant. As single agents, YF476 and loxtidine had essentially equivalent inhibitory effects on gastric apoptosis and atrophy. In addition, combined treatment with both agents tended to have a stronger inhibitory effect on gastric cell apoptosis, although the difference was not significant as compared to the effect of treatment with a single drug.

\section{G-17 Stimulation-Induced Apoptosis and had a Synergistic Effect on FasL-Induced Apoptosis in RGM1-Fas Cells}

In vitro, gastrin-induced apoptosis was examined in rat gastric epithelial cell line RGM-1 cells stably transfected with human Fas antigen (RGM1-Fas cells). FasL stimulation was used as the control for

Figure 8 Immunofluorescence examination of the effect on pit cell hyperplasia in INS-GAS mice with $H$. felis infection of treatment with gastrin/CCK-2 receptor antagonist YF476 and/or H-2 receptor antagonist loxtidine. As compared with that in wild-type FVB/N mice (a), pit cell density labeled by FITC-lectin expression (green) in fundic surfaces was increased in wild-type FVB/N mice with $H$. felis infection. (b) In H. felis infected or uninfected INS-GAS mice at the ages of 8-9 months, pit cell density was also significantly increased, but $H$. felis infection resulted in more significant hyperplasia (d) than occurred in uninfected mice (c). Treatment with either the gastrin/ CCK-2 receptor antagonist YF476 (e) or the H-2 receptor antagonist loxtidine strongly suppressed pit cell hyperplasia (f). Combined treatment with YF476 and loxtidine increased the suppression effect (g). Immunofluorescence staining (original magnification $\times 100$ ). 
the apoptotic effect. FACS analysis showed that, used alone or both of G-17 and FasL stimulation resulted in a significantly increased number of apoptotic cells in RGM1-Fas cells. Notably, when RGM1-Fas cells were stimulated by the combination of G-17 and FasL, a synergistic effect on the
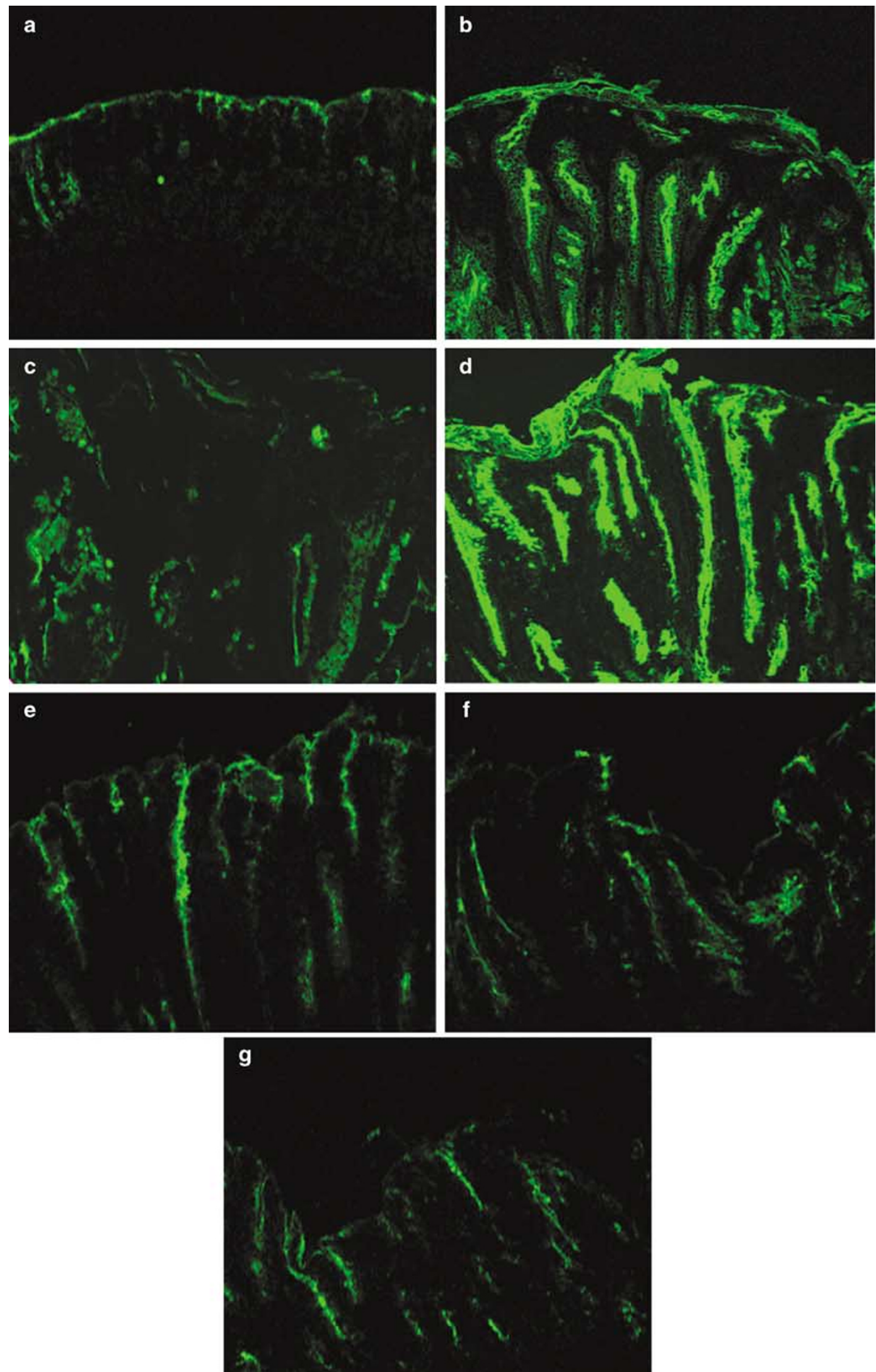

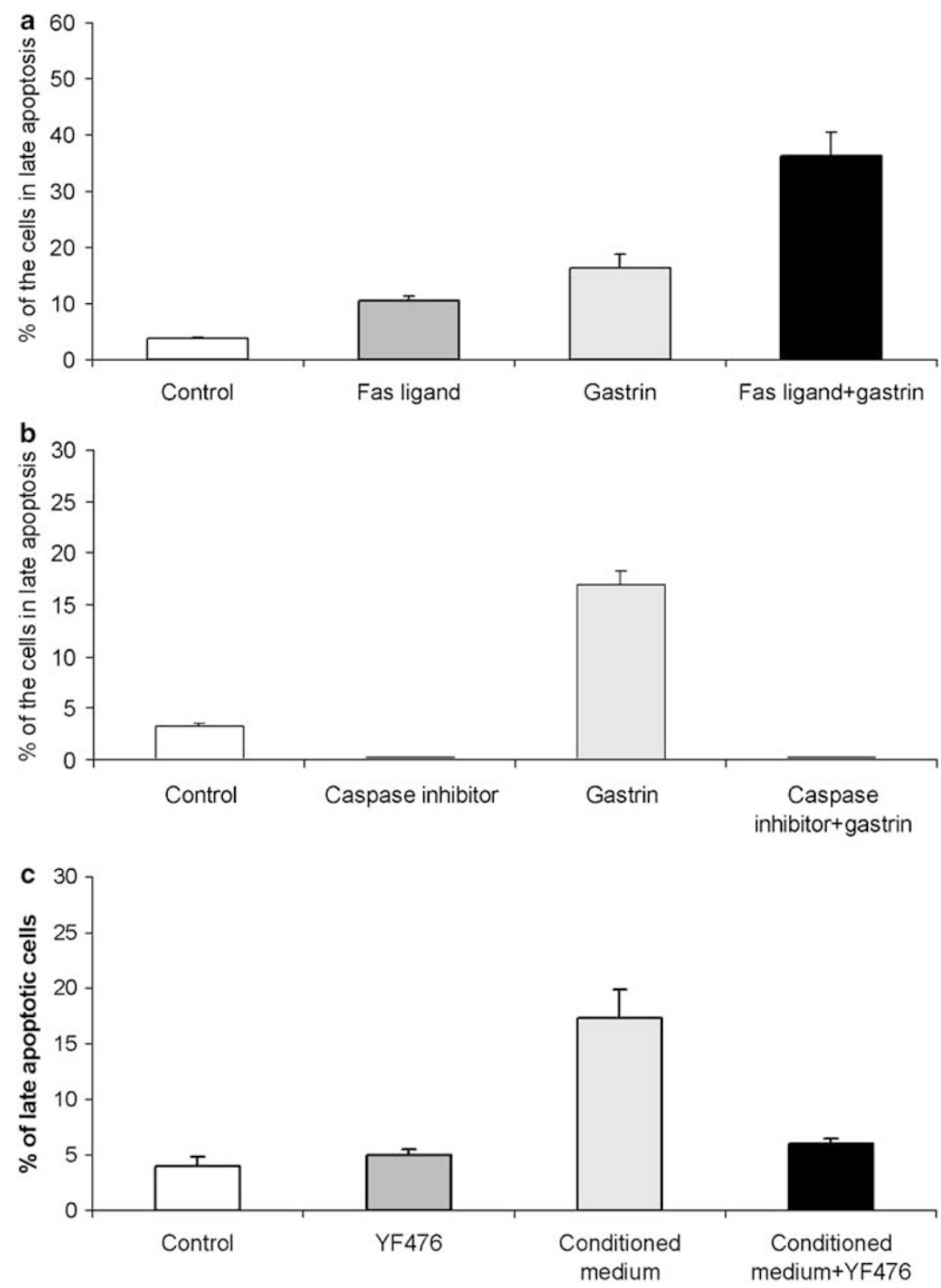

Figure 9 FACS analysis of gastrin-induced apoptosis in Fas-expressing RGM1 cells in vitro. Each experiment was repeated three times; average values were used to show the percentage of cells in late apoptosis. (a) Both gastrin (light gray bar) and FasL (dark gray bar) stimulation induced a 2- to 3-fold increase in apoptosis in Fas-expressing RGM1 cells as compared with control treatment (white bar). When gastrin and FasL were used in combination, a synergized effect was observed, resulting in an approximately seven- to eight-folds increase in apoptosis in Fas-expressing RGM1 cells (black bar). (b) Gastrin-induced cell death (light gray bar) was shown to be apoptosis by the finding that a pan-caspase inhibitor (caspase inhibitor VI) completely blocked the phenotype (caspase inhibitor + gastrin). (c) Gastrin-induced apoptosis occurred via the gastrin/CCK-2 receptor. Conditioned medium was used after $24 \mathrm{~h}$ of $10^{-7} \mathrm{M}$ gastrin treatment of RGM1 cells to induce apoptosis (light gray bar). This apoptosis was abrogated by 30-min pretreatment with CCK-2 receptor antagonist (YF476, $10^{-6} \mathrm{M}$ ) (black bar).

induction of apoptosis was found (Figure 9a). The cell death induced by gastrin was shown to be caused specifically by apoptosis, since a pancaspase inhibitor completely abrogated this effect (Figure 9b). As a control, this caspase inhibitor successfully blocked FasL-induced apoptosis (data not shown). In addition, it appears that gastrin is sufficient to induce apoptosis in gastric cells. In
RGM1 cells pretreated with the CCK-2 receptor antagonist YF476, apoptosis induced by conditioned medium (supernatant of 24-h cell culture treated with $10^{-7} \mathrm{M}$ gastrin) was entirely blocked (Figure 9c). Histamine H2 receptor antagonist loxtidine did not influence the rate of apoptosis in RGM1 cells, since $\mathrm{H} 2$ receptor could not be detected in this cell line (data not shown). 


\section{Discussion}

Previous studies by our group have shown that hypergastrinemia can lead to the acceleration of gastric atrophy, a known preneoplastic condition of the stomach. ${ }^{8,9,12}$ In addition, a possible association between hypergastrinemia and apoptosis has been suggested based on observations in both transgenic (INS-GAS) mice and hypergastrinemic Mastomys. ${ }^{8-10}$ In the current study, using both in vivo and in vitro approaches, we show more directly that hypergastrinemia leads to increased apoptosis of gastric cells. We used gastrin transgenic (INSGAS) and gastrin-deficient (GAS-KO) mice in vivo to illustrate the apoptotic effect of gastrin on gastric cells because they have gastrin levels that are comparable to those in humans ${ }^{4}$ and mice, ${ }^{19}$ which have only a mild increase (two three-fold) in serum gastrin level during the early course of $H$. pylori infection. Our uninfected INS-GAS mice at the age of 2 months show a two-fold elevation in serum gastrin levels, ${ }^{8}$ but this increased over time in association with gradual parietal cell loss and achlorhydria. ${ }^{8}$

At 6 months of $H$. felis infection in INS-GAS mice accelerates the serum gastrin level to $500 \mathrm{pM}$. This is associated with increased parietal cell loss and gastric carcinogenesis throughout the atrophy-metaplasia-carcinoma sequence..$^{8,9,12}$ In this study, the serum gastrin levels in GAS-KO mice infused with gastrin for 8 weeks reached to $514 \mathrm{pM}$, which is comparable to the gastrin level in INS-GAS mice infected for 6 months with H. felis. ${ }^{12}$ Thus, the animal models used in this study could represent the alternation of gastrin and/or morphological changes during gastric carcinogenesis induced by Helicobacter infection. In vitro the use of nontransformed gastric cell line RGM1 allows precise observation of the apoptotic effect of gastrin on a specific gastric cell type.

The finding of an age-associated increase in gastric cell apoptosis in INS-GAS mice was consistent with our earlier observations, which suggested an association between apoptosis and gastric atrophy. ${ }^{8,9,12}$ In the current study, we found that at 2 months of age, apoptosis in INS-GAS mice was observed primarily in glandular (parietal) cells, while at 12 months of age it occurred mainly in pit cells and extraglandular stromal cells. The greater amount of apoptosis in parietal cells at the 2-month time point seems to provide a satisfactory explanation for the later development of gastric atrophy. In GAS-KO mice, 8 weeks of gastrin infusion resulted in increased apoptosis in the middle and lower third regions of gastric glands, and those apoptotic cells were shown by double immunofluorescence staining to be parietal cells. Our current studies showed that there were fewer parietal cells after 8 weeks of infusion than there were after 2 weeks of infusion, ${ }^{13}$ indicating the early onset of gastric atrophy in this model. Taken together, these two model systems suggest that increases in glandular apoptosis of the stomach can be seen with prolonged over-stimulation by amidated gastrin. Interestingly, a similar phenomenon has been reported with respect to enterochromaffin-like (ECL) cells in rats, with 1-2 weeks of gastrin infusion resulting in ECL cell growth, whereas 10-weeks of overstimulation by amidated gastrin led to ECL cell damage and cell death, ${ }^{20}$ although the expression of apoptotic molecules was not investigated in this rat model.

We show that after gastrin infusion hypergastrinemia is associated with alterations in Bcl-2 and Bax in both hypergastrinemic INS-GAS mice and gastrin deficient mice. Bcl-2 belongs to the antiapoptotic gene family, whereas Bax belongs to the family of proapoptotic genes. ${ }^{21}$ With prolonged exposure to hypergastrinemia, the expression of Bax increased over time, whereas Bcl-2 expression gradually declined in glandular regions of the stomach. Previous studies have suggested a correlation between gastrin and alterations in the balance of Bcl-2 and Bax expression. ${ }^{10,22}$ Thus, these results suggest that an altered Bax:Bcl-2 ratio may account for the hypergastrinemia-associated apoptosis observed in these mouse models.

Previous studies by our group have shown that $H$. felis infection of INS-GAS mice exacerbates hypergastrinemia, resulting in a 2.5 -fold higher serum gastrin level than that in uninfected INS-GAS mice, ${ }^{12}$ as well as more rapid progression to atrophy and cancer. In addition, H. felis infection results in significant inflammation ${ }^{12}$ that could contribute to epithelial cell death through apoptotic pathways. To clarify the role of gastrin in the development of gastric atrophy induced by Helicobacter infection, we carried out 1 - and 6-month studies of $H$. felis infection, respectively, and carefully assessed both histology and apoptosis. We observed increased apoptotic parietal cells in INS-GAS mice with 1-month $H$. felis infection and accelerated atrophy in INS-GAS mice infected with 6-month $H$. felis infection, which also showed distorted architecture and few parietal cells. However, increased apoptosis was frequently seen in mesenchymal cells (Figure $6 \mathrm{~d}$ and e) and infiltrating immune cells (Figure 6f). While the significance of this mesenchymal cell apoptosis is not entirely clear, epithelial-mesenchymal interactions are clearly important for normal glandular differentiation and morphogenesis. ${ }^{23,24} \mathrm{In}$ adult mice, stromal disorganization can inhibit the differentiation of parietal cells and chief cells. ${ }^{25}$ Thus, increased apoptosis in extraglandular mesenchymal cells and infiltrating immune cells might contribute to the eventual progression to gastric cancer in $H$. felis-infected INS-GAS mice.

While the effects of gastrin on cellular proliferation and acid secretion have been shown to be mediated by gastrin/CCK-2 receptors, ${ }^{6}$ we have shown in INS-GAS mice this effect is observed in the middle and lower third of gastric glands ${ }^{9}$ where the parietal cells are located. The potential role of 
gastrin in apoptosis has not previously been appreciated. However, treatment with the highly specific gastrin/CCK-2 receptor antagonist YF476 reduced the level of apoptosis and inhibited the development of gastric atrophy. Interestingly, treatment with the irreversible $\mathrm{H}-2$ receptor antagonist loxtidine also inhibited apoptosis and atrophy, and appeared to synergize with YF476 in this process. The inhibitory effects of YF476 and loxtidine on apoptosis and atrophy were equivalent in $H$. felisinfected and uninfected INS-GAS mice. The doses of these drugs used in this study have been shown to significantly inhibit gastric acid secretion and markedly increase serum gastrin level. ${ }^{12}$ The results in this study strongly support the notion that gastrin-induced apoptosis and atrophy are mediated via gastrin/CCK-2 and $\mathrm{H}-2$ receptors. Histamine has been shown to be important in modulating parietal cell maturation through $\mathrm{H}-2$ receptors. ${ }^{26,27}$ Gene targeting of the histidine decarboxylase (HDC) in mice leads to histamine deficiency and increased parietal cell numbers. ${ }^{28,29}$ Given that HDC and histamine are downstream targets of gastrin, ${ }^{6}$ it is conceivable that treatment with YF476 may also inhibit apoptosis, at least partly, indirectly through the downregulation of histamine production.

Nevertheless, a proapoptotic effect of gastrin was confirmed in an untransformed gastric cell line. Using the Fas-expressing rat gastric epithelial cell line RGM1, which also expresses a low level of gastrin/CCK-2 receptor (Ai et al, unpublished observations), we demonstrated an apoptotic effect by gastrin stimulation in vitro through Annexin VFACS analysis. In addition, the finding that a pancaspase inhibitor completely abrogated this effect confirmed that the effect of gastrin on gastric epithelial cells is apoptosis. This apoptosis-inducing effect of gastrin is likely to occur directly via the gastrin/CCK-2 receptor, since the gastrin/CCK-2 receptor antagonist YF476 entirely blocked this effect. In addition, costimulation with FasL and gastrin resulted in a significantly greater apoptosis rate than did stimulation by FasL or gastrin alone. The model is particularly relevant with our study in vivo, since Fas-FasL interactions play an important role in $H$. pylori-induced apoptosis and increased Fas expression has been found in individuals with H. pylori infection. ${ }^{15,30,31}$

While studies have shown that gastrin has antiapoptotic effects in rat AR4-2J pancreatic cancer cells and Barrett's esophagus, ${ }^{32-34}$ other studies have indicated that gastrin can induce apoptosis in colon cancer $^{35,36}$ and cholangiocarcinoma cells. ${ }^{37}$ More recently, hypergastrinemia induced in rats by acid inhibition was reported to increase the expression of apoptosis genes in the stomach. ${ }^{38}$ In current study, the induction of apoptosis by gastrin is notably increased in some gastric cell types, including parietal cells, extraglandular stromal cells, and infiltrating immune cells. The apoptosis index of pit cells was significantly increased, as was the proliferation of these cells. Thus, the effects of gastrin are likely to be cell-type-specific, and the effects in untransformed epithelial cells may be different from those in cancer cells. In addition, while our observations regarding apoptotic effects of gastrin provide a likely explanation for parietal cell loss in our hypergastrinemic animals, the atrophy that occurs in Helicobacter-infected wild-type animals is likely multifactorial and not necessarily due to gastrin stimulation alone. Furthermore, prior studies have suggested that hypergastrinemia-such as that associated with Zollinger-Ellison syndrome or use of proton pump inhibitors-is more typically associated with parietal cell hyperplasia rather than parietal cell loss. However, given this study and prior studies by our group ${ }^{8,9}$ pointing to importance of gastrin processing and the balance of isoforms, it is likely that parietal cell hyperplasia in these clinical settings cannot be attributed to effects of amidated gastrin alone.

In conclusion, gastrin-induced gastric cell apoptosis contributed to gastric carcinogenesis in INSGAS mice with or without Helicobacter infection, and was dependent on gastrin/CCK-2 and H-2 receptor signal pathways. Further clinical studies in patients will be needed to clarify the relationship between elevated gastrin levels and $H$. pyloriinduced gastric carcinogenesis.

\section{Acknowledgements}

This work was supported by a grant from NIH (R01 DK52778) to Dr TC Wang. We thank Dr Keiji Miyata and Dr Hidenobu Yuki, of the Yamanouchi Pharmaceutical Co. Ltd., Tsukuda, Japan, for the gift of YF476, and both Professor Duan Chen, Norwegian University of Science \& Technology, Norway, and Professor Rolf Hakanson, Lund University, Sweden, for the gift of loxtidine.

\section{References}

1 The EUROGAST Study Group. An international association between Helicobacter pylori infection and gastric cancer. Lancet 1993;341:1359-1362.

2 Smith VC, Genta RM. Role of Helicobacter pylori gastritis in gastric atrophy, intestinal metaplasia, and gastric neoplasia. Microsc Res Tech 2000;48:313-320.

3 Correa P. Human gastric carcinogenesis: a multistep and multifactorial process-First American Cancer Society Award Lecture on Cancer Epidemiology and Prevention. Cancer Res 1992;52:6735-6740.

4 Mulholland G, Ardill JE, Fillmore D, et al. Helicobacter pylori related hypergastrinaemia is the result of a selective increase in gastrin 17. Gut 1993;34:757-761.

5 Kuipers EJ, Lundell L, Klinkenberg-Knol EC, et al. Atrophic gastritis and Helicobacter pylori infection in patients with reflux esophagitis treated with omeprazole or fundoplication. N Engl J Med 1996;334: 1018-1022. 
6 Dockray GJ, Varro A, Dimaline R, et al. The gastrins: their production and biological activities. Annu Rev Physiol 2001;63:119-139.

7 Waldum HL, Fossmark R, Bakke I, et al. Hypergastrinemia in animals and man: causes and consequences. Scand J Gastroenterol 2004;39:505-509.

8 Wang TC, Dangler CA, Chen D, et al. Synergistic interaction between hypergastrinemia and Helicobacter infection in a mouse model of gastric cancer. Gastroenterology 2000;118:36-47.

9 Cui G, Koh TJ, Chen D, et al. Overexpression of glycine-extended gastrin inhibits parietal cell loss and atrophy in the mouse stomach. Cancer Res 2004;64: 8160-8166.

10 Kidd M, Tang LH, Modlin IM, et al. Gastrin-mediated alterations in gastric epithelial apoptosis and proliferation in a mastomys rodent model of gastric neoplasia. Digestion 2000;62:143-151.

11 Koh TJ, Goldenring JR, Ito S, et al. Gastrin deficiency results in altered gastric differentiation and decreased colonic proliferation in mice. Gastroenterology 1997; 113:1015-1025.

12 Takaishi S, Cui G, Frederick DM, et al. Synergistic inhibitory effects of gastrin and histamine receptor antagonists on Helicobacter-induced gastric cancer. Gastroenterology 2005;128:1965-1983.

13 Chen D, Zhao CM, Dockray GJ, et al. Glycine-extended gastrin synergizes with gastrin 17 to stimulate acid secretion in gastrin-deficient mice. Gastroenterology 2000;119:756-765.

$14 \mathrm{Li} \mathrm{HC}$, Houghton J. Fas Ag ligation signals for apoptosis or proliferation in gastric mucosal cells: the importance of receptor abundance (abstract). Gastroenterology 2003;124(Suppl):A-595.

15 Houghton J, Macera-Bloch LS, Harrison L, et al. Tumor necrosis factor alpha and interleukin 1beta up-regulate gastric mucosal Fas antigen expression in Helicobacter pylori infection. Infect Immun 2000;68:1189-1195.

16 Strater J, Gunthert AR, Bruderlein S, et al. Microwave irradiation of paraffin-embedded tissue sensitizes the TUNEL method for in situ detection of apoptotic cells. Histochem Cell Biol 1995;103:157-160.

17 Strater J, Wellisch I, Riedl S, et al. CD95 (APO-1/Fas)mediated apoptosis in colon epithelial cells: a possible role in ulcerative colitis. Gastroenterology 1997;113: 160-167.

18 Khan ZE, Wang TC, Cui G, et al. Transcriptional regulation of the human trefoil factor, TFF1, by gastrin. Gastroenterology 2003;125:510-521.

19 Zhao CM, Wang X, Friis-Hansen L, et al. Chronic Helicobacter pylori infection results in gastric hypoacidity and hypergastrinemia in wild-type mice but vagally induced hypersecretion in gastrin-deficient mice. Regul Pept 2003;115:161-170.

20 Kimura K, Chen D, Lindstrom E, et al. Functional impairment of the individual rat stomach ECL cell in response to sustained hypergastrinemia. Regul Pept 1997;72:69-77.

21 Kroemer G. The proto-oncogene Bcl-2 and its role in regulating apoptosis. Nat Med 1997;3:614-620.

22 Mao JD, Wu P, Xia XH, et al. Correlation between expression of gastrin, somatostatin and cell apoptosis regulation gene bcl-2/bax in large intestine carcinoma. World J Gastroenterol 2005;11:721-725.
23 Karam S, Leblond CP. Origin and migratory pathways of the eleven epithelial cell types present in the body of the mouse stomach. Microsc Res Tech 1995; 31:193-214.

24 Tommeras K, Cabero JL, Mardh S. Expression of extracellular matrix proteins in the fetal rat gastric mucosa. Anat Embryol (Berlin) 2000;201:149-156.

25 Fukamachi H. Disorganization of stroma alters epithelial differentiation of the glandular stomach in adult mice. Cell Tissue Res 1986;243:65-68.

26 Ohtsu H, Watanabe T. New functions of histamine found in histidine decarboxylase gene knockout mice. Biochem Biophys Res Commun 2003;305:443-447.

27 Fukushima Y, Matsui T, Saitoh T, et al. Unique roles of $\mathrm{G}$ protein-coupled histamine $\mathrm{H} 2$ and gastrin receptors in growth and differentiation of gastric mucosa. Eur J Pharmacol 2004;502:243-252.

28 Hunyady B, Zolyomi A, Czimmer J, et al. Expanded parietal cell pool in transgenic mice unable to synthesize histamine. Scand J Gastroenterol 2003;38: 133-140.

29 Nakamura E, Kataoka T, Furutani K, et al. Lack of histamine alters gastric mucosal morphology: comparison of histidine decarboxylase-deficient and mast cell-deficient mice. Am J Physiol Gastrointest Liver Physiol 2004;287:G1053-G1061.

30 Lehmann FS, Terracciano L, Carena I, et al. In situ correlation of cytokine secretion and apoptosis in Helicobacter pylori-associated gastritis. Am J Physiol Gastrointest Liver Physiol 2002;283:G481-G488.

31 Rudi J, Kuck D, Strand S, et al. Involvement of the CD95 (APO-1/Fas) receptor and ligand system in Helicobacter pylori-induced gastric epithelial apoptosis. J Clin Invest 1998;102:1506-1514.

32 Todisco A, Ramamoorthy S, Witham T, et al. Molecular mechanisms for the antiapoptotic action of gastrin. Am J Physiol Gastrointest Liver Physiol 2001;280: G298-G307.

33 Stepan V, Ramamoorthy S, Pausawasdi N, et al. Role of small GTP binding proteins in the growth-promoting and antiapoptotic actions of gastrin. Am J Physiol Gastrointest Liver Physiol 2004;287:G715-G725.

34 Harris JC, Clarke PA, Awan A, et al. An antiapoptotic role for gastrin and the gastrin/CCK-2 receptor in Barrett's esophagus. Cancer Res 2004;64:19151919.

35 Yu HG, Schafer H, Mergler S, et al. Valine-286 residue in the third intracellular loop of the cholecystokinin 2 receptor exerts a pivotal role in cholecystokinin 2 receptor mediated intracellular signal transduction in human colon cancer cells. Cell Signal 2005;17: 1505-1515.

36 Muerkoster S, Isberner A, Arlt A, et al. Gastrin suppresses growth of CCK2 receptor expressing colon cancer cells by inducing apoptosis in vitro and in vivo. Gastroenterology 2005;129:952-968.

37 Kanno N, Glaser S, Chowdhury U, et al. Gastrin inhibits cholangiocarcinoma growth through increased apoptosis by activation of $\mathrm{Ca} 2+$-dependent protein kinase C-alpha. J Hepatol 2001;34:284-291.

38 Norsett KG, Laegreid A, Langaas M, et al. Molecular characterization of rat gastric mucosal response to potent acid inhibition. Physiol Genom 2005;22: 24-32. 